\title{
Ureterolithotripsy under Spinal Anesthesia in Pompe Disease (Glycogen Storage Disease Type 2): A Case Report
}

\author{
Arzu Acar, Mustafa Nuri Deniz, Elvan Erhan, Gulden Ugur \\ Department of Anaesthesiology and Reanimation, School of Medicine, Ege University, Izmir, Turkey. \\ Email: acararzu@yahoo.com.tr,mnurideniz@hotmail.com,nez_ser@yahoo.com, hoayan2011@yahoo.com
}

Received January $3^{\text {rd }}, 2013$; revised February $6^{\text {th }}, 2013$; accepted February $17^{\text {th }}, 2013$

\begin{abstract}
Pompe disease is an autosomal recessive inherited glycogen storage disease, usually respiratory muscles, cardiac muscle and skeletal muscles are affected in childhood and mortality is inevitable but has a slower progression in the adult. The patient was a 35-year-old male patient who was scheduled to undergo ureterorenoscopy due to right ureteral stone. He was diagnosed with pompe disease after detection of myopathy on EMG due to muscle weakness in the legs and hips. He was started on myozyme vials once every 15 days. Spinal anesthesia with $3 \mathrm{ml} 0.5 \%$ hyperbaric bupivacaine was performed and adequate sensorial and motor block was achieves at $\mathrm{T}_{10}$ level. The surgery was completed with no complications and he was discharged two days later. The selection of appropriate anesthetic technique and a careful perioperative and postoperative monitoring are of utmost importance due to progressive muscle weakness, hypotonia, respiratory failure and cardiomyopathy in pompe disease.
\end{abstract}

Keywords: Pompe Disease; Spinal Anesthesia; Ureterorenoscopie

\section{Introduction}

Pompe disease (glycogen storage disease type II) is an autosomal resessive inherited glycogen storage disorder resulting from the deficiency of acid alpha glucosidase (glycogen debranching enzyme, acid maltase) [1]. This enzyme is responsible for degradation of glycogen polymers into glucose in lysosomes which are found within cardiac and skeletal muscles known as two major glycolgen storage tissues [2]. Cardiomyopathy and skeletal myopathy are observed in patients with complete enzyme deficiency resulting in death during first year of life [2]. Mortality is due to hypotonia, generalized myopathy, cardiomyopathy and respiratory failure. In the adult form, acid alpha glucosidase enzyme is usually present, though in insufficient amount, and this form of the disease has a slower progression $[3,4]$. Skeletal myopathy eventually develops respiratory failure patients with partial enzyme deficiency [2]. Metabolic myopathy is due to a defect in muscular metabolism presenting as exercise intolerance or a progressive muscle weakness [5].

Enzyme replacement therapy with alglucosidase alfa [myozyme; recombinant human acid alpha glucosidase (rhGAA)] can be used in all forms of the disease [6]. Enzyme replacement therapy is effective in the protection of cardiac muscle in infants but its effect in skeletal muscles falls short of expectations [4].

The manifestations of pompe disease which are muscle weakness, hypotonia, respiratory failure, cardiomyopathy necessitate appropriate selection of anesthetic technique and careful perioperative monitoring. This study presents the anesthetic management of a patient with pompe disease undergoing ureterorenoscopy (URS) due to ureteral stone in the urology clinic.

\section{Case}

A 35-year-old male patient (weight $82 \mathrm{~kg}$ ) who was scheduled to undergo ureterorenoscopie (URS) due to right ureteral stone was diagnosed with pompe disease by further examinations performed after the detection of myopathy on electromyography (EMG) due to muscle weakness in the legs and hips 5 months ago. The patient was started on myozyme vials (alphaglucosidase preparation) once every 15 days. His medical history revealed inguinal hernia repair surgery under general anesthesia without any adverse events 3 years ago and the diagnosis of pompe disease at that time. On physical examination, PA chest radiography, electrocardiography (ECG), laboratory tests and respiratory function test revealed normal findings. The patient was given no pre-medication. After transfer to the operating room, the patient's ECG, arterial blood pressure (ABP), heart rate (HR) and $\mathrm{SpO}_{2}$ were monitored and peripheral vascular access was accomplished by placing an $18 \mathrm{G}$ angiocatheter. The patient, scheduled to undergo spinal anesthesia, had an ABP of 
102/44 $\mathrm{mmHg}$, $\mathrm{HR}$ of $73 / \mathrm{min}$, and $\mathrm{SpO}_{2}$ of $97 \%$ before the procedure. With the patient in the sitting position, spinal anesthesia was performed at the L3-L4 interspace with a 26 -Gauge atraucan spinal needle using $0.5 \%$ hyperbaric bupivacaine $3 \mathrm{ml}$. The patient was taken to lithotomy position and $1 \mathrm{mg}$ midazolam was administered intravenously for sedation. The patient with normal hemodynamic parameters developed motor and sensory block at T10 level in 3 minutes and the 30-minute surgery was completed with no complications. At the end of surgery, his ABP was $107 / 65 \mathrm{mmHg}$, HR was $87 / \mathrm{min}$, $\mathrm{SpO}_{2}$ was $95 \%$ and after 3 hours the sensorimotor block had regressed completely. The patient with an uncomplicated postoperative period was discharged from the hospital 2 days later.

\section{Discussion}

Pompe disease presenting in early childhood is associated with hypertrophic cardiomyopathy, and an increased risk of cardiac arrhythmia and these patients suffer from diastolic heart failure and elevated left ventricular end diastolic pressure [7]. In the adult form of pompe disease, cardiac muscle is unaffected and muscle weakness is the primary symptom [4]. Enzyme replacement therapy with alglucosidase alpha has been reported to fall short of expectations in skeletal muscles [4]. Though reported to be effective in the protection of cardiac muscles, Wang et al. [8] retrospectively reviewed the experiences of 139 patients treated with rhGAA enzyme replacement and reported cardiac arrhythmia or cardiopulmonary arrest after the induction of general anesthesia in 9 patients $(6 \%)$. Induction was performed with propofol in 4 patients but with sevoflurane without propofol in 2 patients. The authors concluded that propofol or high concentrations of sevoflurane should be avoided in the anesthetic management of patients with pompe disease and instead, an agent such as ketamine should be used in order to support coronary perfusion for induction and to avoid decreasing diastolic blood pressure with vasolidatory agents. On the other hand some authors suggest to prefer regional anesthesia in patients with pompe disease because of the potential problems associated with general anesthesia [9]. Walker et al. [9] performed femoral nerve block or caudal epidural block in five patients with infantile form of pompe disease for 11 quadriceps biopsies. The authors suggested that regional anesthesia techniques in this highrisk group are a good alternative for some surgical procedures. Since there was a potential to cause sympathetic blockade and afterload reduction in an infant with hypertrophic cardiomyopathy, the authors task the measures to counter this and drew attention to the fact that the anesthetists should fully understand the pathophysiology of the condition before performing regional blocks to these patients. Most of the information about anesthesia for pompe disease comes from those presenting in infancy or early childhood. There are few case reports of adults with pompe disease and the anesthetic management. Ciliers et al. [10] reported the first case of the spinal anesthesia for caesarean section and successful live birth in a patient with pompe disease. They suggested that adult Pompe patients had mild cardiac problems whereas they might suffer from impaired respiratory function, hypotonia, scoliosis, and macroglossia and a spinal or epidural anesthesia might be difficult by the presence of scoliosis and macroglossia might make ventilation and intubation difficult. They also suggested that succinylcholine is contraindicated because of the risk of increased $\mathrm{K}^{+}$secretion due to muscle damage in these patients [10]. Therefore, they performed caesarean section using combined spinal and epidural anesthesia in a 31-year-old patient at 37 weeks of gestation with known Pompe disease whose pulmonary function test revealed obstructive and restrictive pattern, resulting in the birth of a healthy baby without any complications [10]. The selection of appropriate anesthetic technique and a careful perioperative and postoperative monitoring are of utmost importance due to progressive muscle weakness, hypotonia, respiratory failure and cardiomyopathy in pompe disease. In the light of these data, we preferred spinal anesthesia in our patient recently diagnosed with pompe disease who had muscle weakness but no severe cardiac and respiratory complications and observed no complications during or after surgery. Therefore we suggest using regional techniques including central blocks for patients with pompe disease, wherever it is suitable for the surgical procedure.

\section{REFERENCES}

[1] M. Sakakibara, Y. Teramoto, T. Aoyama, T. Takahashi, M. Hara, M. Maseki and S. Yamaguchi, "A Case Report of Anesthesia for a Child with Pompe's Disease (Glycogen Storage Disease Type II)," Masui, Vol. 58, No. 2, 2009, pp. 219-222.

[2] T. Fukuda, A. Roberts, P. H. Plotz and N. Raben, "Acid Alphaglucosidase Deficiency (Pompe Disease)," Current Neurology and Neuroscience Reports, Vol. 7, No. 1, 2007, pp. 71-77. doi:10.1007/s11910-007-0024-4

[3] Z. Illés and A. Trauninger, "Pompe's Disease. Part I: Pathogenesis and Clinical Features," Ideggyogyaszati Szemle, Vol. 62, No. 6-7, 2009, pp. 231-243.

[4] B. Schoser, V. Hill and N. Raben, "Therapeutic Approaches in Glycogen Storage Disease Type II/Pompe Disease," Neurotherapeutics, Vol. 5, No. 4, 2008 pp. 569578. doi:10.1016/j.nurt.2008.08.009

[5] P. Laforêt, M. Nicolino and B. Eymard, "New Approaches for the Treatment of Metabolic Myopathies," Revue Neurologique, Vol. 163, No. 10, 2007, pp. 930-935. doi:10.1016/S0035-3787(07)92636-3

[6] A. Amallfitano, A. R. Bengur, R. P. Morse, et al., "Recombinant Human Acid a Glucosidase Enzyme Therapy 
for İnfantile Glycogen Storage Disease Type II: Results of Phase I/II Clinical Trial," Genetics in Medicine, Vol. 3, No. 2, 2001, pp. 132-138.

[7] P. S. Kishnani, R. D. Steiner, D. Bali, et al., "Pompe Disease Diagnosis and Management Guideline," Genetics in Medicine, Vol. 8, No. 5, 2006, pp. 267-288. doi:10.1097/01.gim.0000218152.87434.f3

[8] L. Y. Wang, A. K. Ross, J. S. Li and S. M. Dearmey, "Cardiac Arrhythmias Following Anesthesia İnduction in İnfantile-Onset Pompe Disease: A Case Series," Pediatric Anesthesia, Vol. 17, No. 8, 2007, pp. 738-748.

doi:10.1111/j.1460-9592.2007.02215.x
[9] R. W. Walker, G. Briggs, J. Bruce, J. Fletcher and E. D. Wraith, "Regional Anesthetic Techniques Are an Alternative to General Anesthesia for İnfants with Pompe's Disease," Pediatric Anesthesia, Vol. 17, No. 7, 2007, pp. 697-702. doi:10.1111/j.1460-9592.2007.02196.x

[10] H. J. Cilliers, S. T. Yeo and N. P. Salmon, “Anaesthetic Management of an Obstetric Patient with Pompe Disease," International Journal of Obstetric Anesthesia, Vol. 17, No. 2, 2008, pp. 170-173. doi:10.1016/j.ijoa.2007.11.001 